\title{
A Low-Profile Reflector-Enhanced Drop-Shaped Printed Antenna for Wide-Band Wireless Communications
}

\author{
Giovanni Cappelletti, ${ }^{1}$ Diego Caratelli, ${ }^{2,3}$ Renato Cicchetti, ${ }^{4}$ Claudio Gennarelli, ${ }^{5}$ \\ Massimiliano Simeoni, ${ }^{6}$ and Orlandino Testa ${ }^{4}$ \\ ${ }^{1}$ Leonardo S.p.A., Cisterna di Latina, Italy \\ ${ }^{2}$ The Antenna Company, Eindhoven, Netherlands \\ ${ }^{3}$ Tomsk Polytechnic University, Tomsk, Russia \\ ${ }^{4}$ Department of Information Engineering, Electronics and Telecommunications, University of Rome "La Sapienza", \\ Via Eudossiana No. 18, 00184 Rome, Italy \\ ${ }^{5}$ Department of Industrial Engineering, University of Salerno, Salerno, Italy \\ ${ }^{6}$ European Space Agency (ESTEC), 2200 AG Noordwijk, Netherlands
}

Correspondence should be addressed to Renato Cicchetti; cicchetti@die.uniromal.it

Received 30 December 2016; Accepted 28 March 2017; Published 21 May 2017

Academic Editor: N. Nasimuddin

Copyright (C) 2017 Giovanni Cappelletti et al. This is an open access article distributed under the Creative Commons Attribution License, which permits unrestricted use, distribution, and reproduction in any medium, provided the original work is properly cited.

\begin{abstract}
An improved low-profile printed antipodal drop-shaped dipole antenna for wide-band wireless applications is presented. The proposed radiating structure is integrated with a planar metal reflector useful to enhance antenna gain up to $5.5 \mathrm{dBi}$ and the frontto-back ratio up to $21 \mathrm{~dB}$. The geometry of reflector, feeding line, and dipole arms is optimized in order to achieve a broad operating bandwidth useful to meet the requirements of modern wireless communication protocols. Furthermore, the particular shape of the metal reflector and the adoption of a thin low-permittivity dielectric substrate result in a low distortion of the radiated field and a limited back radiation which makes the antenna suitable for UWB applications as well. These features, together with the low profile and the limited occupation area, make the antenna well adapted to mobile terminals as well as radio base stations. A locally conformal FDTD numerical procedure has been adopted to design and analyse the radiating structure, while a SEM technique has been employed to highlight the field perturbation caused by the antenna reflector as well as to extract the characteristics underlying the transient behaviour of the antenna. The experimental measurements performed on an antenna prototype are found to be in good agreement with the numerical computations.
\end{abstract}

\section{Introduction}

Wide-band antennas, having low profile and reduced manufacturing costs, are finding widespread interest in the industrial and the scientific community [1-18]. This interest is dictated by the numerous applications such as those concerning the wireless communications [1-14], the automotive transportation [19-21], the remote screening of biological activities [22-24], as well as the analysis of the ground subsurface $[25,26]$, and through-the-wall radar imaging. Moreover, they may be used to realize UWB systems for short-range and indoor wireless communications characterized by low transmission-power consumption and high immunity to multipath interferences [27]. In addition, the growing demand for portable and/or wearable devices is further expanding the application ranges of such antennas [15-18]. In this context, antennas designed to support UWB signals, that is, such as to ensure a low distortion of the radiated signals, can be used in both wide-band wireless applications and pulsed radio communications. These design goals cannot be achieved with all classes of broadband antennas, or by using antennas realized with thick dielectric substrates having high permittivity, they being potentially responsible for dispersive phenomena and, in turn, by a significant signal distortion [28]. 
To overcome these limitations a low-profile printed dropshaped dipole antenna for wide-band and UWB communications has been recently introduced in the literature [4]. This antenna is characterized by a reduced occupation area, a large operating bandwidth, a limited signal distortion, and a good rejection of the spurious backward radiation in the direction of the feeding line, where the sensitive electronic circuitry adopted to process the RF signal is typically located. Even though said antenna exhibits excellent electromagnetic performance, in some applications it may be useful to employ an antenna having a higher gain along the broadside direction, as well as a more limited emission in the direction of the feeding line. To this end, in this paper a low-profile drop-shaped antenna provided with a planar metal reflector is presented. This antenna, which is intended for wireless applications, is useful to meet the demanding requirements of different communication standards, such as WLAN/WiMAX and UWB protocols. Similarly to the drop-shaped dipole antenna presented in [4], the proposed antenna can be used in stand-alone or array configuration.

The paper is organized in five sections. In Section 2, the electromagnetic performances of the proposed antenna are analysed; in Section 3 the radiation characteristics of the antenna are presented, while in Section 4 the time-domain characteristics are derived and discussed in detail. Finally, some concluding remarks are given in Section 5.

\section{Full-Wave Analysis of the Drop-Shaped Antenna Equipped with a Planar Metal Reflector}

The geometry of the proposed antenna is sketched in Figure 1, while its physical prototype is shown in Figure 2. The antenna consists of a printed dipole whose radiating arms have a droplike shape similar to that proposed in [4], whereas the ground plane is modified in order to play the role of a planar reflector, whose geometry is defined by means of arcs of ellipses having main axes and centres as shown in Figure 1.

Two design formulas, describing the profiles of the feeding line and of the reflector in terms of simple parameters, have been adopted to simplify the design of the antenna. The following analytical expression, introduced in [4] to model the feeding line profile, has been employed:

$$
x_{f}=\frac{2 l_{t}}{\pi} \cos ^{-1}\left[\left(\frac{2|z|-w_{t}}{w_{f}-w_{t}}\right)^{1 / \alpha}\right] \quad \frac{w_{t}}{2} \leq|z| \leq \frac{w_{f}}{2}
$$

where the parameters $w_{f}, w_{t}$ are the width of the initial and final sections of the tapered feeding line of length $l_{t}$ having tapering parameter $\alpha$. On the other side of the board (see Figure 1(b)), a suitable reflector, whose boundary profile is the combination of arcs of ellipses, is printed. In particular, its geometry is described by the following expression:

$$
x_{\text {ref }}= \begin{cases}c_{x 2}-A_{x 2 \text { ref }} \sqrt{1-\left(\frac{|z|-c_{z 2}}{A_{z 2 \text { ref }}}\right)^{2}} & z_{c} \leq|z| \leq z_{s} \\ c_{x 1}-A_{x 1 \text { ref }} \sqrt{1-\left(\frac{|z|-c_{z 1}}{A_{z 1 \text { ref }}}\right)^{2}} & |z|>z_{s},\end{cases}
$$

where the parameters $A_{x 1 \text { ref }}, A_{z 1 \text { ref }}$ identify the semiaxes and $c_{x 1}, c_{z 1}$ the centres of the ellipse describing the reflector boundary, while $A_{x 2 \text { ref }}, A_{z 2 \text { ref }}$ and $c_{x 2}, c_{z 2}$ describe the tapering of the feeding line protruding from the ground plane.

In (2), $z_{s}$ denotes the point where the two curves match. To guarantee the continuity of the first derivative of function (2) at the matching point $z_{s}$, the following relations between the above parameters have to be employed:

$$
\begin{aligned}
c_{x 1} & =c_{x 2}+\sqrt{1-\left(\frac{z_{s}-c_{z 2}}{A_{z 2 \mathrm{ref}}}\right)^{2}}\left\{\frac{A_{x 1 \mathrm{ref}}^{2} / A_{z 1 \mathrm{ref}}}{\sqrt{\left(A_{x 2 \mathrm{ref}} / A_{z 2 \mathrm{ref}}\right)^{2}+\left[\left(A_{x 1 \mathrm{ref}} / A_{z 1 \mathrm{ref}}\right)^{2}-\left(A_{x 2 \mathrm{ref}} / A_{z 2 \mathrm{ref}}\right)^{2}\right]\left[1-\left(\left(z_{s}-c_{z 2}\right) / A_{z 2 \mathrm{ref}}\right)^{2}\right]}}\right. \\
& \left.-A_{x 2 \mathrm{ref}}\right\}, \\
c_{z 1} & =z_{s}-\frac{A_{z 1 \mathrm{ref}} A_{x 2 \mathrm{ref}}\left(\left(z_{s}-c_{z 2}\right) / A_{z 2 \mathrm{ref}}^{2}\right)}{\sqrt{\left(A_{x 2 \mathrm{ref}} / A_{z 2 \mathrm{ref}}\right)^{2}+\left[\left(A_{x 1 \mathrm{ref}} / A_{z 1 \mathrm{ref}}\right)^{2}-\left(A_{x 2 \mathrm{ref}} / A_{z 2 \mathrm{ref}}\right)^{2}\right]\left[1-\left(\left(z_{s}-c_{z 2}\right) / A_{z 2 \mathrm{ref}}\right)^{2}\right]}} .
\end{aligned}
$$

In (3),

$$
c_{z 2}=z_{c}+A_{z 2 \mathrm{ref}} \sqrt{1-\left(\frac{x_{c}-c_{x 2}}{A_{x 2 \mathrm{ref}}}\right)^{2}}
$$

where $x_{c}$ and $z_{c}$ identify the point where the curve describing the contour of reflector (2) is joined with the feeding line profile described in (1). All the parameters describing the geometry of the reflector are shown in Figure 3 for the sake of clarity.

Notice that, thanks to the full parameterization of the geometrical profile of the antenna, an automatic design procedure can be usefully adopted in order to ensure a proper $50 \Omega$ impedance matching over a wide frequency range. 


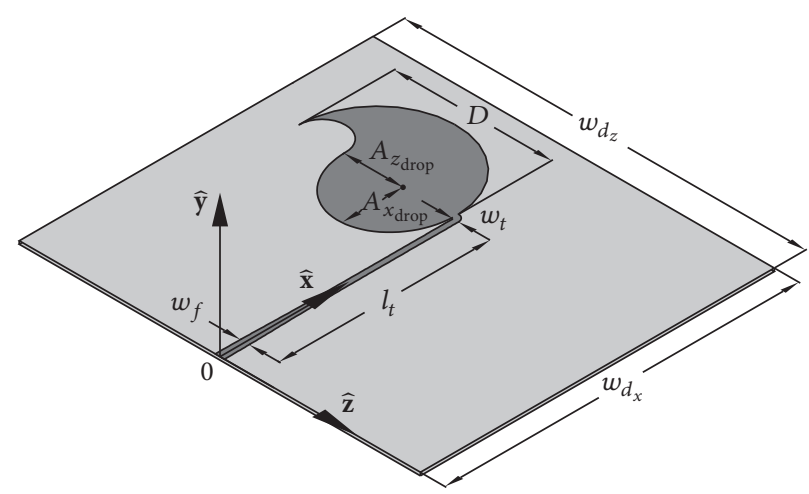

(a)

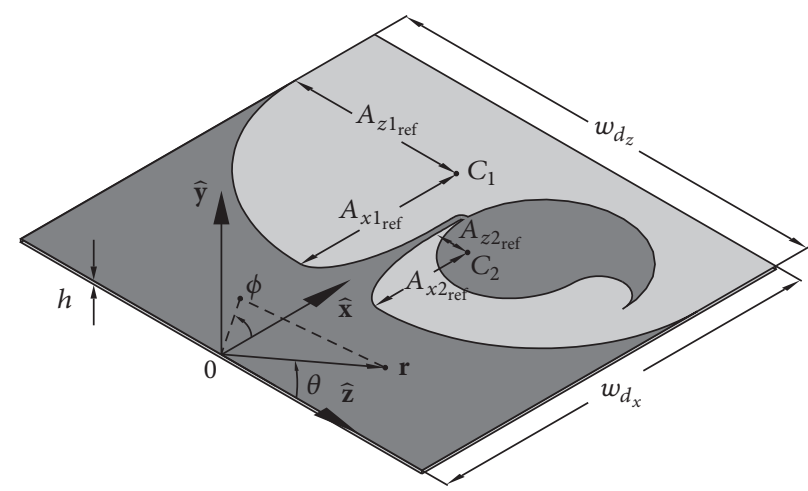

(b)

FIGURE 1: Geometry of the drop-shaped antipodal dipole antenna equipped with a metal reflector: (a) upper face, (b) top view of the lower face. The reference system used to analyse the radiating structure is also shown.

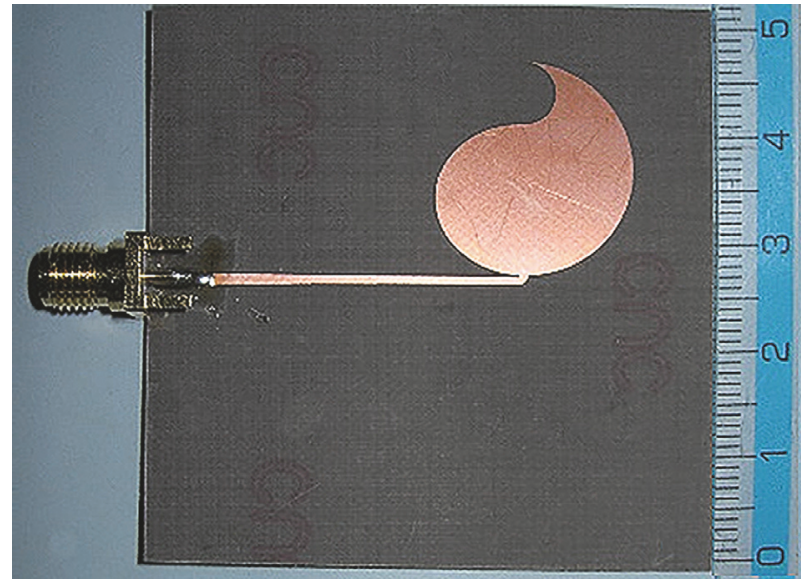

(a)

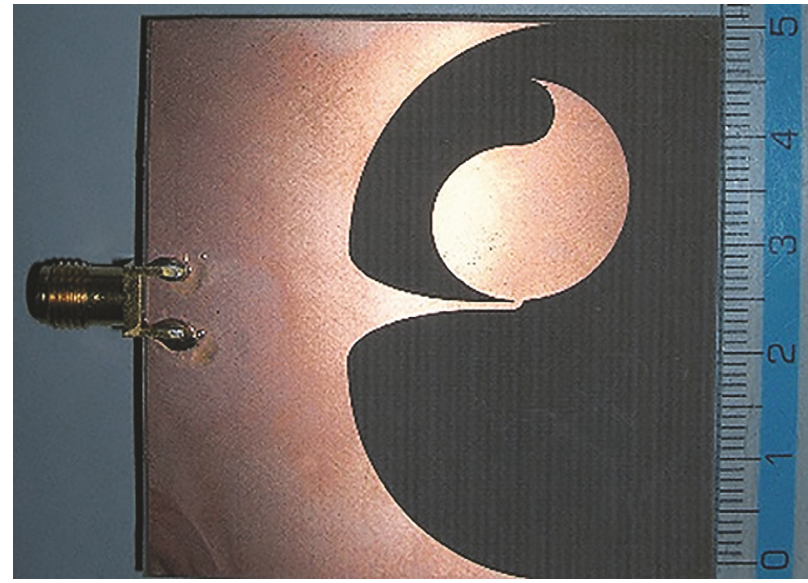

(b)

Figure 2: Prototype of the drop-shaped antipodal dipole antenna equipped with a metal reflector: (a) top view, (b) bottom view.

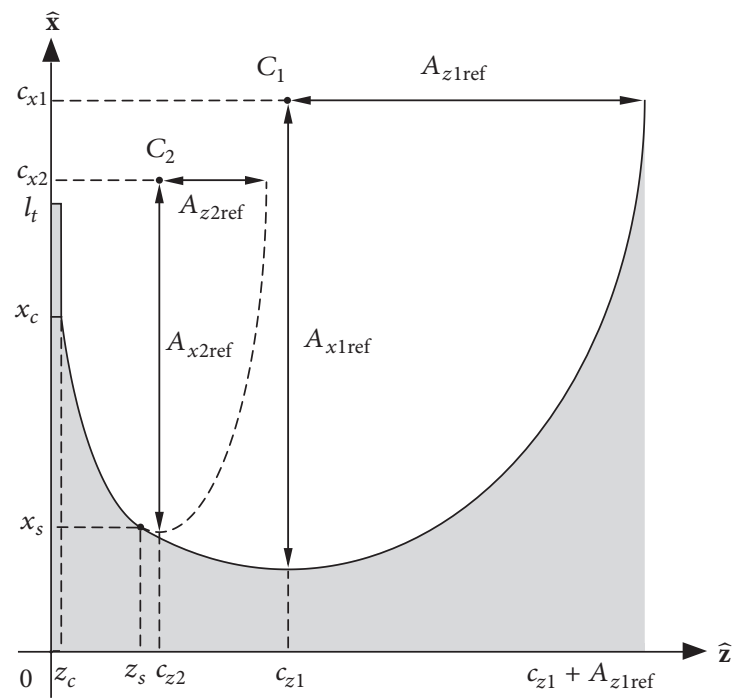

FIGURE 3: Schematic showing the geometry of the reflector together with all the parameters used to describe its boundary. Due to the structure symmetry, only the region for $z>0$ is shown in the figure. 
TABLE 1: Parameters describing the geometry of the drop-shaped antenna equipped with the metal reflector.

\begin{tabular}{lccc}
\hline$A_{x 1 \text { ref }}$ & $20 \mathrm{~mm}$ & $x_{c}$ & $26.6 \mathrm{~mm}$ \\
$A_{z 1 \text { ref }}$ & $20.5 \mathrm{~mm}$ & $w_{d x}$ & $45 \mathrm{~mm}$ \\
$A_{x 2 \text { ref }}$ & $11.6 \mathrm{~mm}$ & $w_{d z}$ & $51 \mathrm{~mm}$ \\
$A_{z 2 \text { ref }}$ & $4.65 \mathrm{~mm}$ & $D$ & $20 \mathrm{~mm}$ \\
$A_{x \text { Drop }}$ & $7 \mathrm{~mm}$ & $w_{f}$ & $1.15 \mathrm{~mm}$ \\
$A_{z \text { Drop }}$ & $8 \mathrm{~mm}$ & $c_{x 1}$ & $35 \mathrm{~mm}$ \\
$w_{t}$ & $0.7 \mathrm{~mm}$ & $c_{z 1}$ & $5 \mathrm{~mm}$ \\
$l_{t}$ & $30 \mathrm{~mm}$ & $c_{x 2}$ & $26.6 \mathrm{~mm}$ \\
$\alpha$ & 10 & $c_{z 2}$ & $5 \mathrm{~mm}$ \\
$z_{c}$ & $0.35 \mathrm{~mm}$ & $z_{s}$ & $5 \mathrm{~mm}$ \\
\hline
\end{tabular}

In order to evaluate the performance of the proposed drop-shaped dipole antenna integrated with a metal reflector, the same geometrical dimensions and dielectric material adopted in [4] for the substrate have been employed. This means that the radiating element is printed on a dielectric substrate (CuClad217) having dimensions $w_{d_{x}}=45 \mathrm{~mm}$ and $w_{d_{y}}=51 \mathrm{~mm}$, relative dielectric permittivity $\varepsilon_{r}=2.17$, $\tan \delta=0.0009$ at $10 \mathrm{GHz}$, and thickness $h=0.38 \mathrm{~mm}$, approximately equal to about $0.6 \%$ of the free-space wavelength at the working frequency of $f=5 \mathrm{GHz}$. Since the radiative properties of the antenna are strongly affected by the geometry of the feeding line and of the metal reflector, a thorough investigation has been carried out in order to ensure a proper $50 \Omega$ impedance matching.

So, after confirming the suitability of the feeding line profile (1) with $\alpha=10$, and $w_{f}, w_{t}$ and $l_{t}$ as indicated in [4], to cover the UWB band, a particular attention has been devoted to the design of the metal reflector. To this end an extensive parametric analysis, useful to optimize the radiative characteristics of the antenna, has been carried out by means of a full-wave locally conformal finite-difference time-domain (FDTD) numerical technique [3]. In Table 1, the optimized values of all the parameters defining the antenna geometry, computed using the mentioned FDTD numerical technique, are reported.

By way of example, in Figures 4-7 the frequency behaviour of the magnitude of the antenna input reflection coefficient $\Gamma_{\text {in }}$, obtained when the geometrical reflector parameters $A_{x 1 \text { ref }}, A_{x 2 \text { ref }}, A_{z 1 \text { ref }}$, and $A_{z 2 \text { ref }}$ change, is reported. From the analysis of these figures it appears that the parameter $A_{x 2 \text { ref }}$, which identifies the distance of the antenna radiating arms from the edge of the metal reflector, has a significant impact on the antenna impedance matching contrary to the others geometrical parameters $A_{x 1 \text { ref }}, A_{z 1 \text { ref }}$, and $A_{z 2 \text { ref }}$. In fact, variations in the order of about one millimetre around the optimum value can impair the frequency behaviour of the antenna, increasing the value of the lower operative frequency or reducing the $-10 \mathrm{~dB}$ margin of the reflection coefficient.

Finally, Figure 8 shows the frequency behaviour of the reflection coefficient of the drop-shaped printed dipole antenna equipped with a metal reflector, as modelled by using

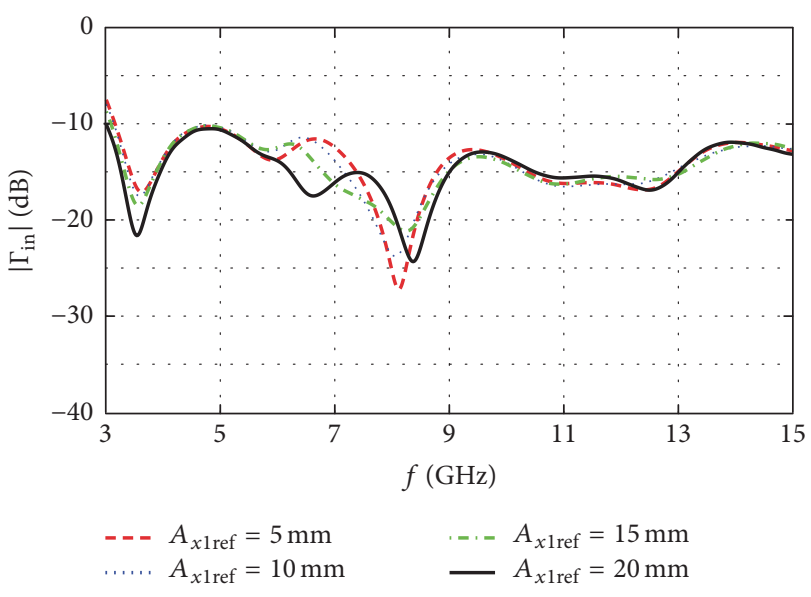

FIgURE 4: Magnitude of the input reflection coefficient versus frequency for the drop-shaped dipole antenna equipped with a metal reflector computed for different values of the parameter $A_{x 1 \text { ref }}$. Structure characteristics: $w_{t}=0.7 \mathrm{~mm}, l_{t}=30 \mathrm{~mm}, D=20 \mathrm{~mm}$, $A_{z 1 \mathrm{ref}}=20.5 \mathrm{~mm}, A_{x 2 \mathrm{ref}}=11.6 \mathrm{~mm}$, and $A_{z 2 \mathrm{ref}}=4.65 \mathrm{~mm}$.

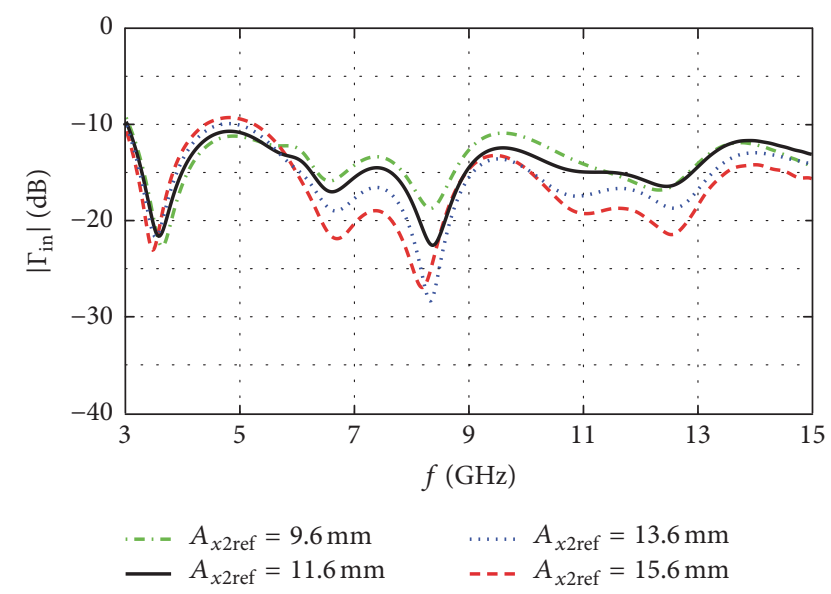

FIGURE 5: Magnitude of the input reflection coefficient versus frequency for the drop-shaped dipole antenna equipped with a metal reflector computed for different values of the parameter $A_{x 2 \text { ref }}$. Structure characteristics: $w_{t}=0.7 \mathrm{~mm}, l_{t}=30 \mathrm{~mm}, D=20 \mathrm{~mm}$, $A_{x 1 \mathrm{ref}}=20 \mathrm{~mm}, A_{z 1 \mathrm{ref}}=20.5 \mathrm{~mm}$, and $A_{z 2 \mathrm{ref}}=4.65 \mathrm{~mm}$.

the mentioned FDTD technique and as measured on the antenna prototype shown in Figure 2.

As it appears in Figure 8, the proposed antenna features a bandwidth larger than $10 \mathrm{GHz}$ at $10 \mathrm{~dB}$ return-loss level (VSWR $<2: 1$ ) and a bandwidth of about $12 \mathrm{GHz}$ at $6 \mathrm{~dB}$ return-loss level (VSWR $<3: 1$ ); both results are similar to those observed for the antenna without reflector [4]. A good agreement between the FDTD numerical results and the experimental measurements can be noticed.

\section{The Radiation Characteristics of the Antenna}

Using the computed electromagnetic field values, the spatial distribution of the surface current density excited on the 


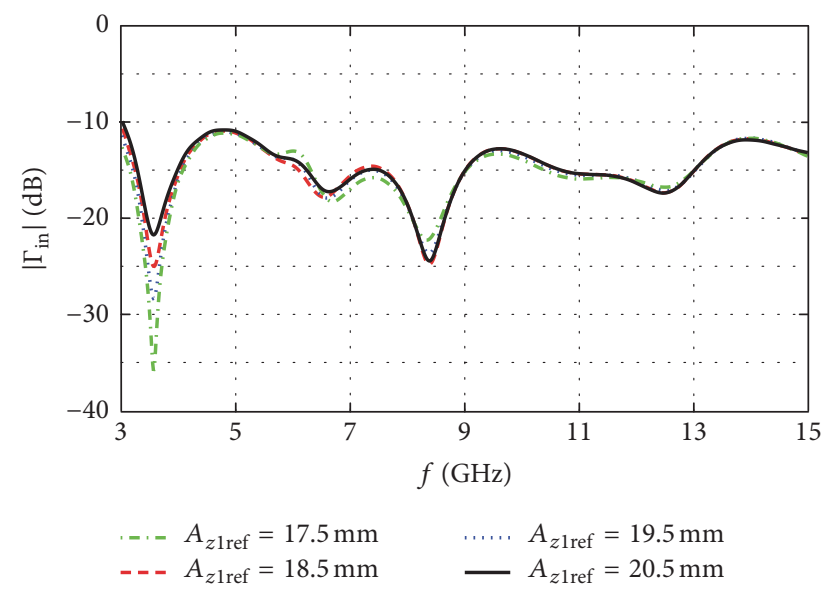

FIGURE 6: Magnitude of the input reflection coefficient versus frequency for the drop-shaped dipole antenna equipped with a metal reflector computed for different values of the parameter $A_{z 1 \text { ref }}$. Structure characteristics: $w_{t}=0.7 \mathrm{~mm}, l_{t}=30 \mathrm{~mm}, D=20 \mathrm{~mm}$, $A_{x 1 \mathrm{ref}}=20 \mathrm{~mm}, A_{x 2 \mathrm{ref}}=11.6 \mathrm{~mm}$, and $A_{z 2 \mathrm{ref}}=4.65 \mathrm{~mm}$.

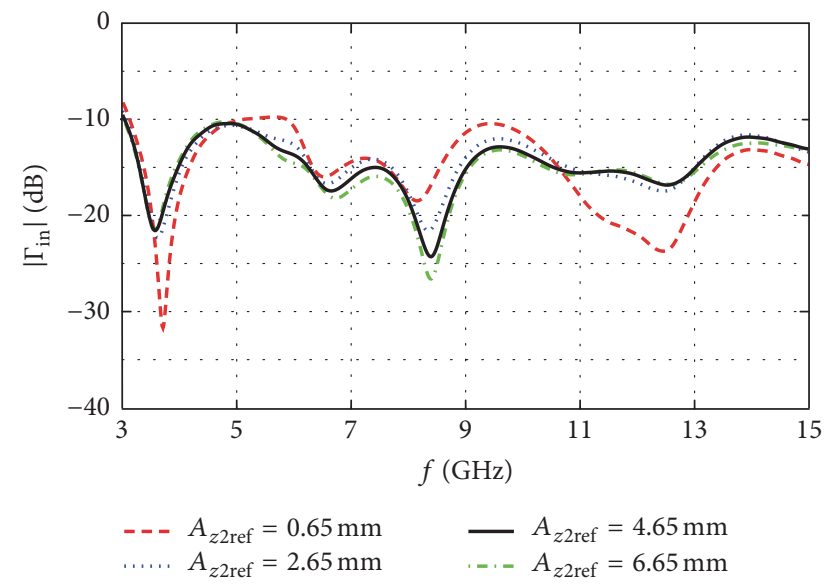

FIGURE 7: Magnitude of the input reflection coefficient versus frequency for the drop-shaped dipole antenna equipped with a metal reflector computed for different values of the parameter $A_{z 2 \text { ref }}$. Structure characteristics: $w_{t}=0.7 \mathrm{~mm}, l_{t}=30 \mathrm{~mm}, D=20 \mathrm{~mm}$, $A_{x 1 \mathrm{ref}}=20 \mathrm{~mm}, A_{z 1 \mathrm{ref}}=20.5 \mathrm{~mm}$, and $A_{x 2 \mathrm{ref}}=11.6 \mathrm{~mm}$.

reflector and on the dipole arms, as well as the real part of the Poynting vector, and the radiation patterns (see Figure 9) have been evaluated at the working frequencies of $5 \mathrm{GHz}$, $6 \mathrm{GHz}$, and $7 \mathrm{GHz}$, both for the antenna with and without metal reflector. Moreover, for the sake of completeness, the frequency behaviour of the maximum antenna gain and of the front-to-back ratio is reported in Figure 10.

The maps relevant to the surface current densities, not reported here for the sake of brevity, show that the surface currents are mainly confined along the edges of the reflector and of the radiating arms of the antenna and exhibit a global maximum in proximity of the excitation region. Although the behaviour of the currents excited on the radiating arms of the antenna is similar to the case presented in [4], the presence of

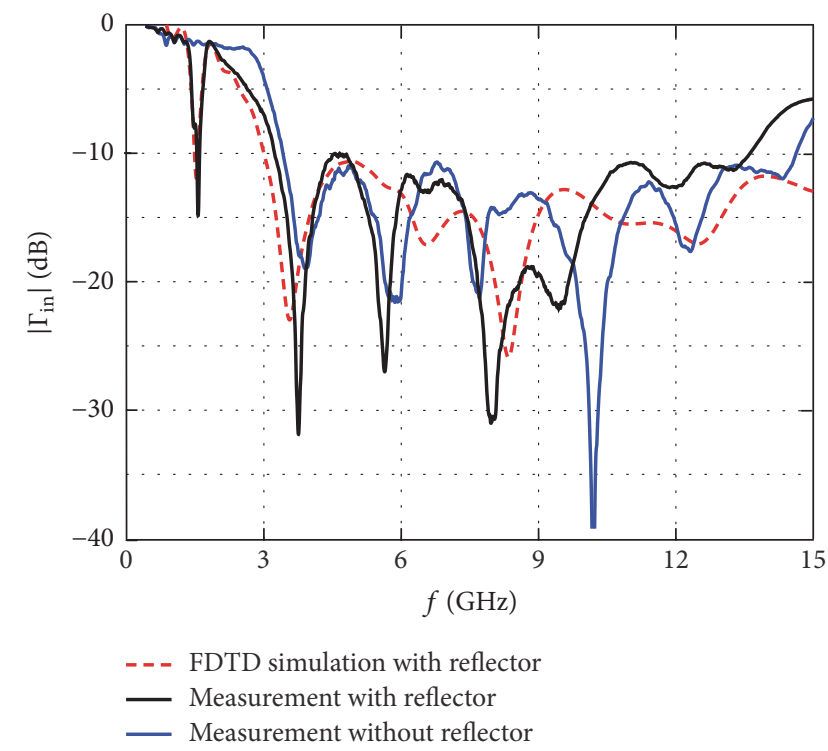

FIGURE 8: Magnitude of the input reflection coefficient versus frequency for the drop-shaped dipole antenna equipped with and without metal reflector. A good agreement between the FDTD numerical result and the experimental measurement is observed.

the metal reflector determines an enhancement of the quasitraveling wave behaviour of the radiated electromagnetic field already at low frequencies, namely, at $4 \mathrm{GHz}$. This particular behaviour leads to an increment of the field level radiated along the broadside direction which reaches its maximum effectiveness at about $6 \mathrm{GHz}$, where the antenna gain exhibits an enhancement of about $4 \mathrm{~dB}$ along the desired direction and, at the same time, a reduction of about $10 \mathrm{~dB}$ in the backward direction.

Starting from the frequency of about $8 \mathrm{GHz}$ the field focusing effect along the broadside direction tends to weaken due to the formation of antenna beams pointing in directions different from that of the boresight even though the reflector ensures, anyway, a reduction of the backward radiation level in the direction of the feeding line.

These results are confirmed by the analysis of the spatial distribution of the real part of the Poynting vector computed in the $x z$-plane at the air-dielectric interface (see Figure 11). The computed vector maps show that the electromagnetic energy is guided along the profile of the drop-shaped radiating arms and of the antenna reflector. This results in a larger radiation level at the boresight, as well as in a reduced energy emission in the backward direction. This important feature, often overlooked in antenna design, can be exploited to reduce the electromagnetic coupling with the RF circuitry hosted in the same board [29]. The peak gain, the mainlobe direction, and the antenna beamwidth in the E-plane $\left(\phi=0^{\circ}\right)$ at different working frequencies are listed in Table 2. The reported values confirm the good performance of the proposed antenna.

\section{Time-Domain Antenna Behaviour}

The results presented in previous sections have shown that an integrated reflector can improve the performance of the 


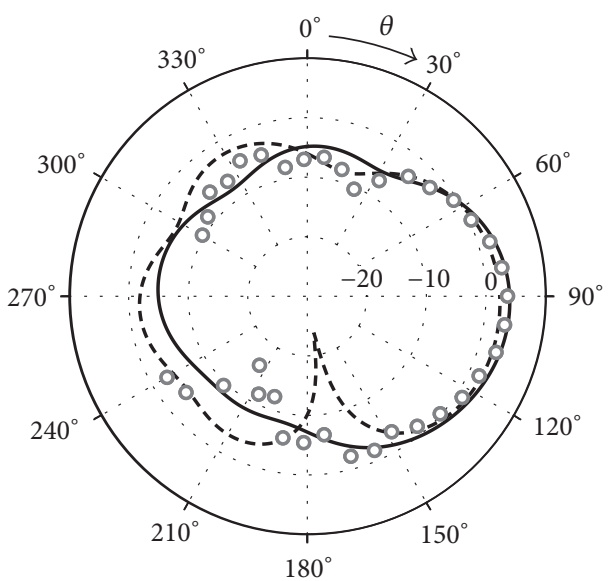

— Drop with reflector - - - Drop without reflector

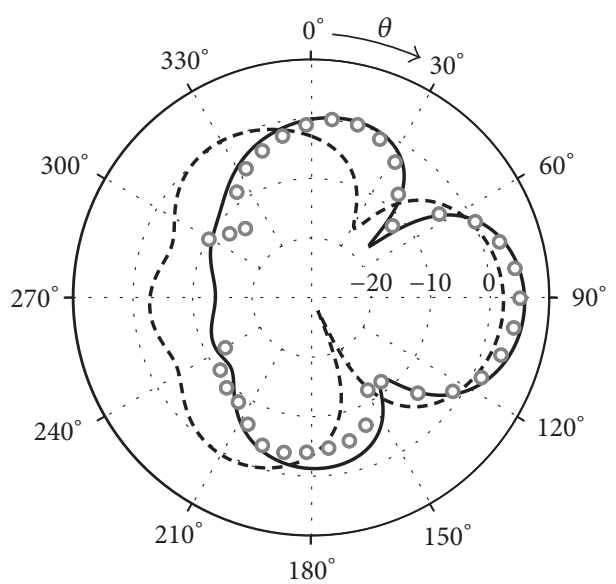

— Drop with reflector - - - Drop without reflector

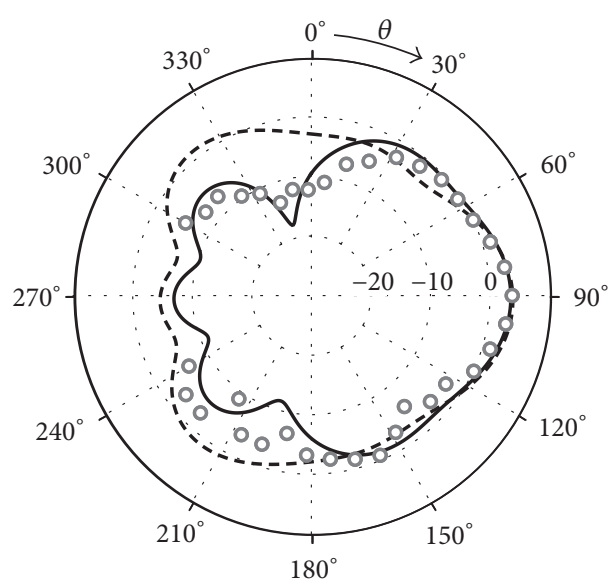

_. Drop with reflector

○ $\bigcirc$ Measurements

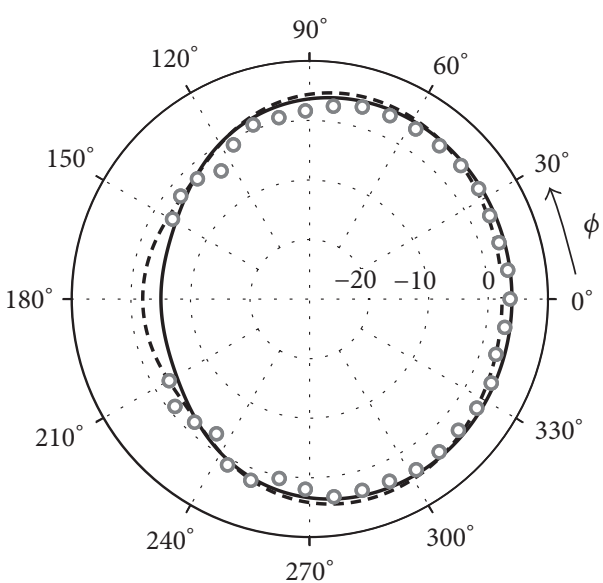

- Drop with reflector - - - Drop without reflector

(a)

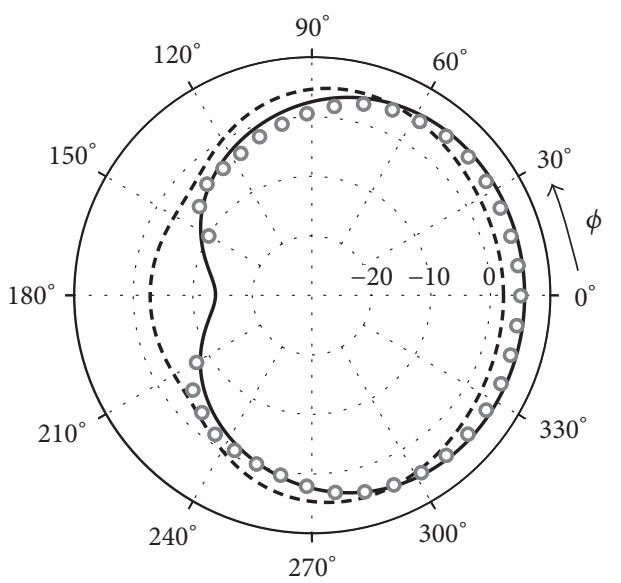

_ Drop with reflector $\quad \circ$ Measurements

(b)

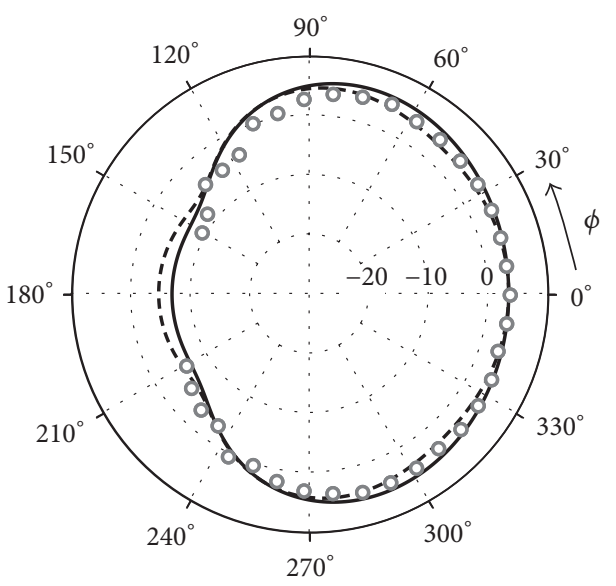

_- Drop with reflector

○ $\bigcirc$ Measurements

(c)

Figure 9: Antenna gain patterns in the $E$-plane (left side) and in the $H$-plane (right side) for the drop-shaped dipole antenna with and without reflector. Working frequency: (a) $5 \mathrm{GHz}$, (b) $6 \mathrm{GHz}$, and (c) $7 \mathrm{GHz}$. An enhanced quasi-traveling wave behaviour is observed in the radiation patterns relevant to the drop-shaped dipole antenna equipped with the metal reflector. 


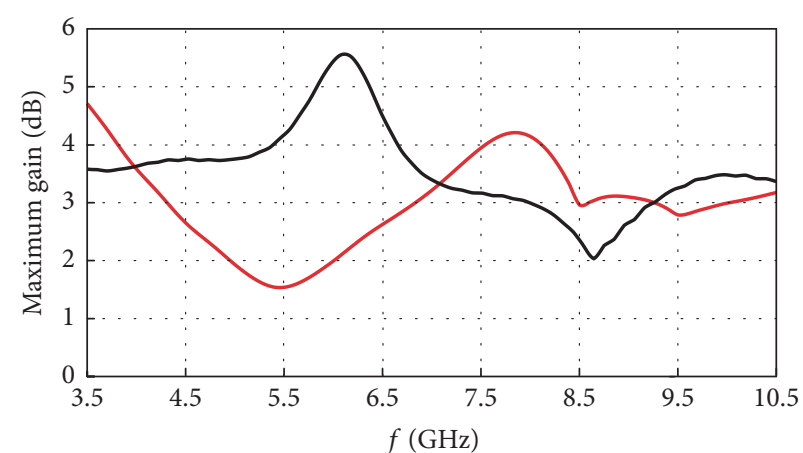

— Max gain with reflector
Max gain without reflector

(a)

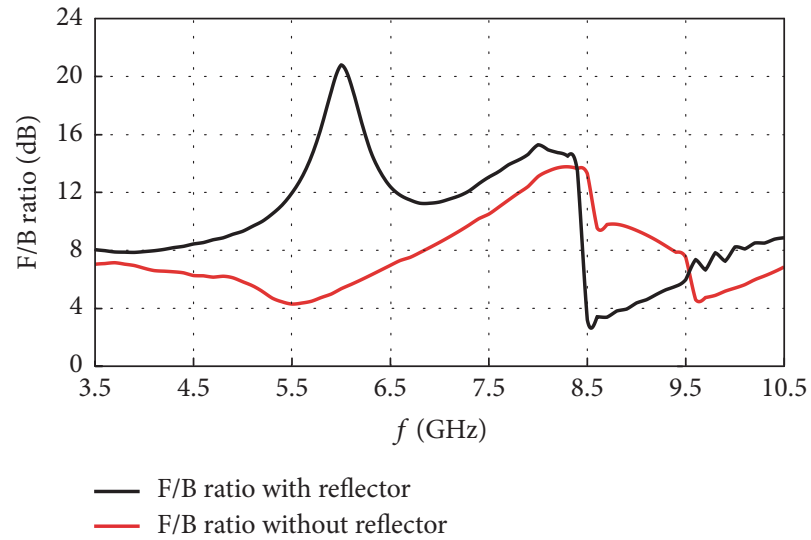

(b)

FIGURE 10: Frequency behaviour of the maximum antenna gain (a) and front-to-back ratio (b). As it can be observed the reflector improves the maximum antenna gain in the frequency range where the main wireless applications, as well as the spectrum of the UWB pulse signals, fall [14]. In addition, it improves the antenna front-to-back ratio, this being beneficial for a larger electrical insulation with the RF circuitry.

TABLE 2: Parameters describing the radiation characteristics of the antenna.

\begin{tabular}{|c|c|c|c|c|c|c|c|c|}
\hline \multirow[t]{2}{*}{ Freq. (GHz) } & \multicolumn{2}{|c|}{ Beamwidth } & \multicolumn{2}{|c|}{$\begin{array}{c}\text { Max gain }(\mathrm{dBi}) \\
\text { E-plane }\left(\phi=0^{\circ}\right)\end{array}$} & \multicolumn{2}{|c|}{$\begin{array}{c}\text { Pointing angle } \theta \\
\text { for } \phi=0^{\circ}\end{array}$} & \multicolumn{2}{|c|}{$\mathrm{F} / \mathrm{B}$ ratio $(\mathrm{dB})$} \\
\hline & No reflector & With reflector & No reflector & With reflector & No reflector & With reflector & No reflector & With reflector \\
\hline 4 & $78^{\circ}$ & $85.9^{\circ}$ & 3.9 & 3.6 & $95^{\circ}$ & $101^{\circ}$ & 6.8 & 7.9 \\
\hline 5 & $81^{\circ}$ & $69^{\circ}$ & 2.1 & 3.8 & $100^{\circ}$ & $96^{\circ}$ & 5.8 & 9.3 \\
\hline 6 & $58^{\circ}$ & $42.8^{\circ}$ & 1.8 & 5.5 & $95^{\circ}$ & $93^{\circ}$ & 5.4 & 20.8 \\
\hline 7 & $50^{\circ}$ & $52.7^{\circ}$ & 3.3 & 3.4 & $96^{\circ}$ & $91^{\circ}$ & 8.6 & 11.3 \\
\hline 8 & $48^{\circ}$ & $88.9^{\circ}$ & 4.0 & 3.0 & $95^{\circ}$ & $92^{\circ}$ & 13.1 & 15.3 \\
\hline 9 & $58^{\circ}$ & $51.3^{\circ}$ & 3.1 & 3.2 & $25^{\circ}$ & $51^{\circ}$ & 9.4 & 4.4 \\
\hline 10 & $40^{\circ}$ & $33.7^{\circ}$ & 2.9 & 3.7 & $130^{\circ}$ & $131^{\circ}$ & 5.4 & 8.2 \\
\hline
\end{tabular}

drop-shaped antenna in terms of gain and front-to-back ratio in a wide frequency range. Since these characteristics result from the specific field distribution determined by the reflector, an unavoidable alteration of the antenna response to the radiated pulse signals is expected in comparison to the antenna element without reflector. To this end, in this section, an analysis of the time-domain antenna response is performed in order to determine the impact of the reflector. This survey may be useful in the development of a new class of low-profile antennas aimed at the transmission/reception of UWB signals.

Typical excitation signals used to determine the suitability of wide-band antennas to transmit pulsed signals are those based on the higher order derivative of the Gaussian pulse. In this context, the antenna excitation signal has been selected to be the fifth derivative of the Gaussian pulse

$$
\begin{aligned}
s(t)= & c_{s} \frac{t-t_{0}}{\sigma^{6}}\left[-15+10\left(\frac{t-t_{0}}{\sigma}\right)^{2}-\left(\frac{t-t_{0}}{\sigma}\right)^{4}\right] \\
& \cdot e^{-(1 / 2)\left(\left(t-t_{0}\right) / \sigma\right)^{2}}
\end{aligned}
$$

where $t_{0}$ defines the time at which the Gaussian pulse exhibits the peak value, whereas $\sigma$ denotes the relevant variance.
The suitability of the antenna to work with impulsive signals has been verified by means of the analysis of the timedomain response and of the relative group delay, which properly quantifies the propagation properties of the so-called wave packet [28]. To this end, in Figure 12 the frequency behaviour of the relative group delay of the antenna with and without metal reflector in the frequency band $3-11 \mathrm{GHz}$ is shown, while the corresponding time-domain responses are reported in Figure 13.

Both these quantities have been evaluated at a distance of $30 \mathrm{~cm}$ from the centre of the dipole arms, under the assumption that the input signal, with parameters $t_{0}=300 \mathrm{ps}$ and $\sigma=51 \mathrm{ps}$, is characterized by a peak value of $1 \mathrm{~V}$.

The analysis of the frequency behaviour of the relative group delay reported in Figure 12 reveals the presence of a peak at a frequency of about $10 \mathrm{GHz}$. This peak, however, does not jeopardize the overall time-domain behaviour of the antenna since it is located at the upper edge of the UWB band. In fact, the peak magnitude is below $1 \mathrm{~ns}$ and, accordingly, the group delay is compliant with the UWB requirements [30]. Such conclusion is confirmed by the time-domain response of the antenna shown in Figure 13.

From this figure it appears that the presence of the reflector does not affect negatively the quality of the radiated signal 


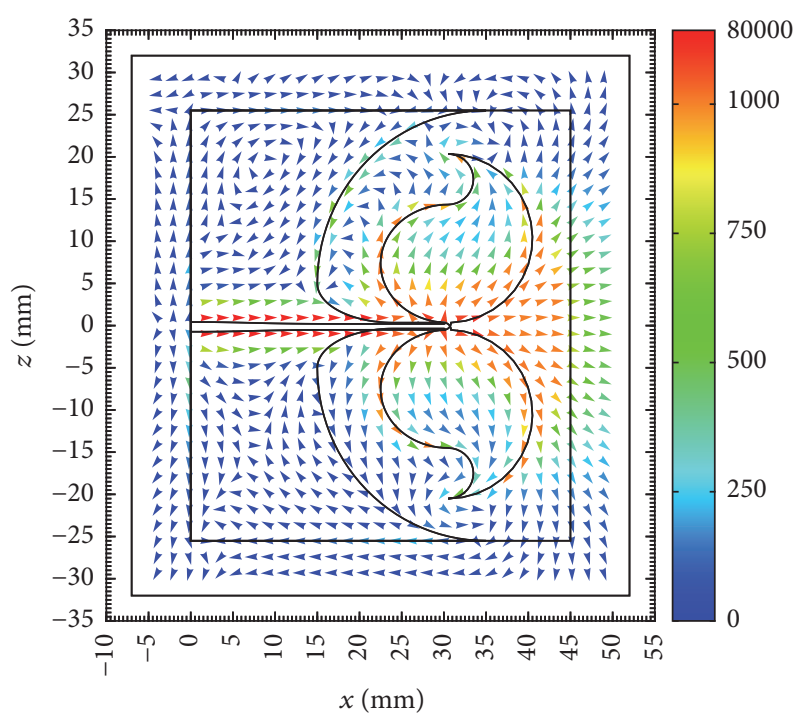

(a)

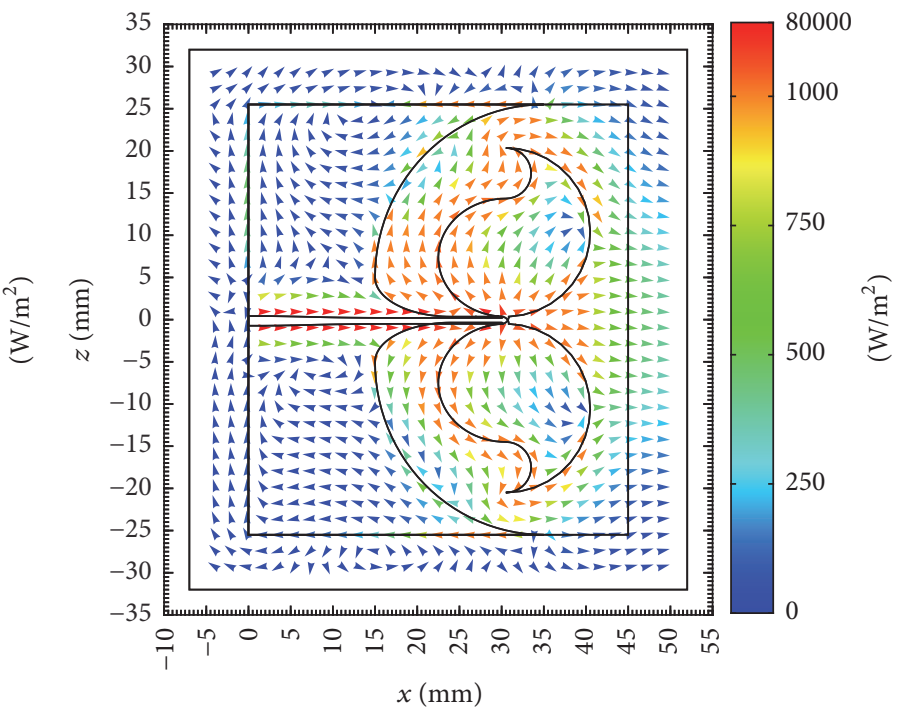

(b)

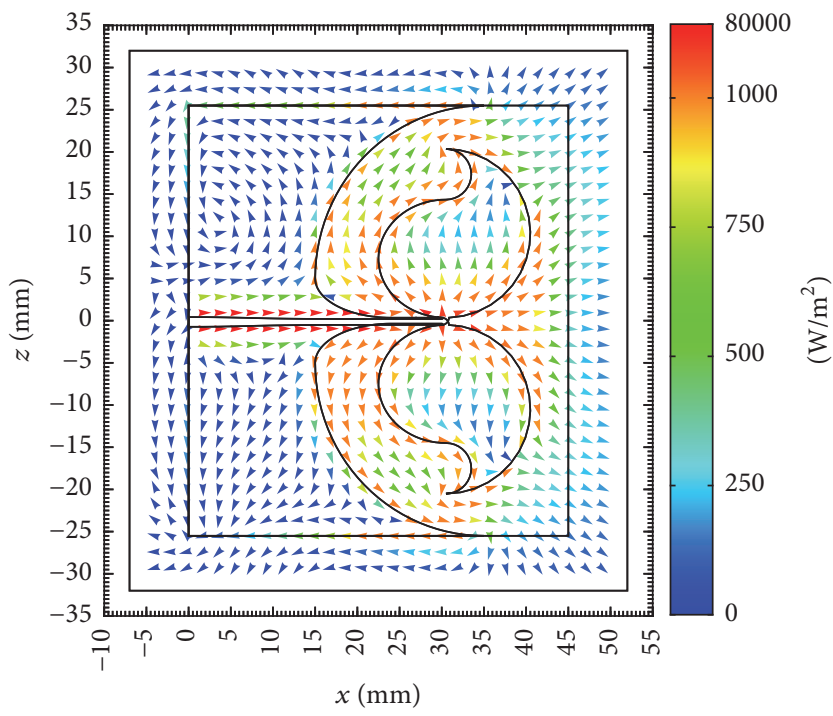

(c)

FIGURE 11: Spatial distribution of the real part of the Poynting vector in the $x z$-plane at the air-dielectric interface. Working frequency (a) $f=5 \mathrm{GHz}$, (b) $f=6 \mathrm{GHz}$, and (c) $f=7 \mathrm{GHz}$. An interesting guiding effect of the electromagnetic energy along the back-side contour of the antenna arms and a quasi-traveling field behaviour enhanced by the metal reflector is observed in the radiated power density flux at the frequency of $f=6 \mathrm{GHz}$.

while allowing a reduction of the electromagnetic energy emitted in the direction of the feeding line. In particular, the level of radiated signals at the boresight is quite similar for both antenna configurations, while a 50\% reduction of the peak-to-peak level of the signal radiated in the direction of the feeding line is observed in the reflector integrated antenna, making the use of such radiating structure more appealing when tackling coexistence issues with sensitive electronic devices sharing the same board.

Further information about the electromagnetic behaviour of the proposed antenna can be achieved by means of the Singularity Expansion Method (SEM) technique [31]. This technique, in fact, enables deriving information about the complex resonant processes taking place in the structure, allowing gaining a physical insight into the transient emission phenomena responsible for the structure behaviour. To this end, the radiative component of the electric field evaluated along the boresight direction is expressed as follows:

$$
\begin{aligned}
& E_{z}(x, s) \approx \frac{1}{x} \sum_{q=1}^{N_{\mathrm{pol}}} s \frac{R_{z_{q}} e^{-s(x / c)}}{s-s_{q}} I_{0}(s), \\
& E_{y}(x, s) \approx 0,
\end{aligned}
$$

where $s$ is the Laplace variable, $I_{0}(s)$ is the current excited at the SMA connector, $c$ is the light velocity in vacuum, and $N_{\text {pol }}$ is the number of the considered poles, while $s_{q}=\sigma_{q}+j \omega_{q}$ 


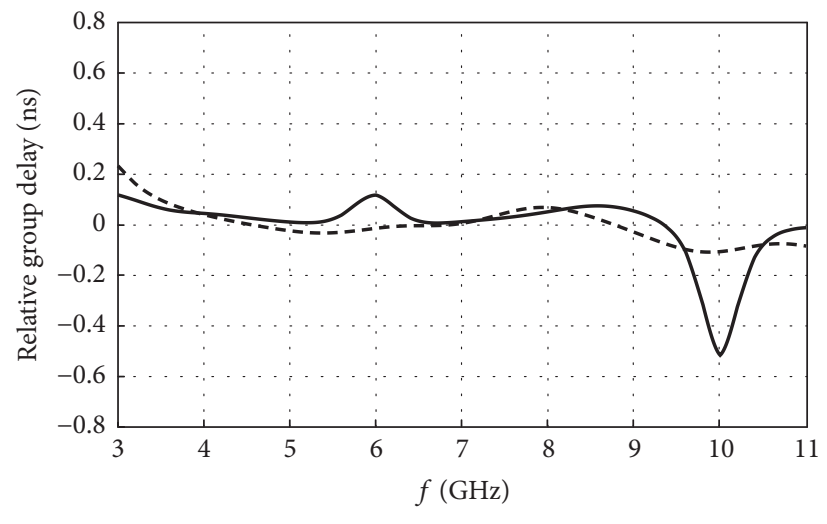

- Drop dipole with reflector

- - - Drop dipole without reflector

FIGURE 12: Frequency behaviour of the group delay featured by the antenna with and without metal reflector. The presence of a peak appearing at the end of the UWB band does not jeopardize the good radiation performance of the proposed antenna.

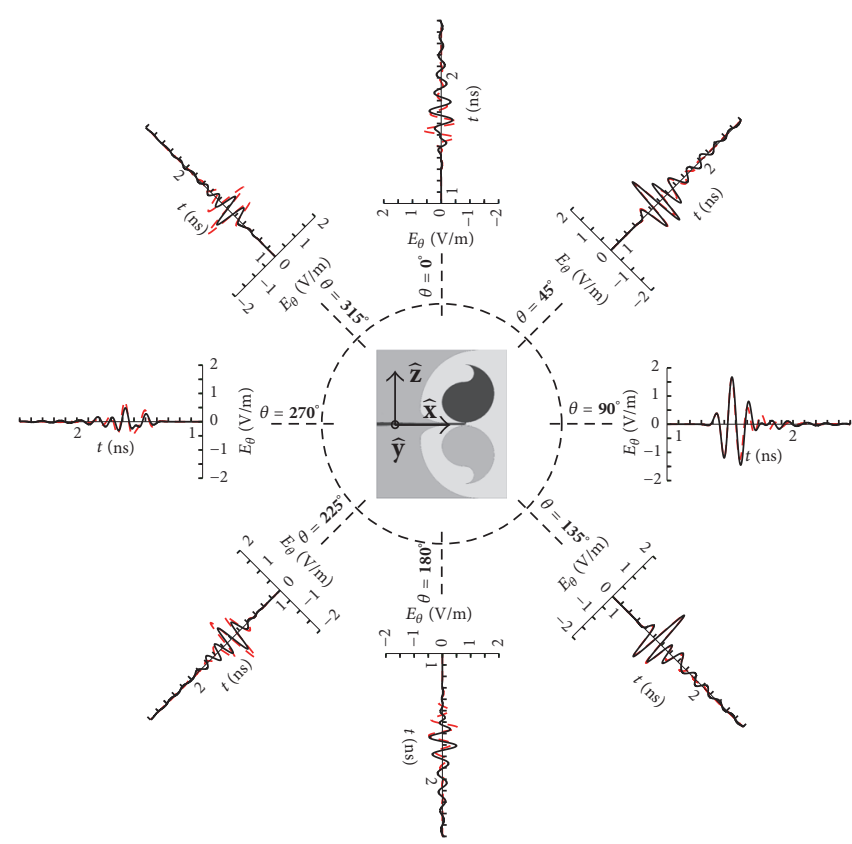

— Drop dip. with reflector
- - Drop dip. without reflector

(a)

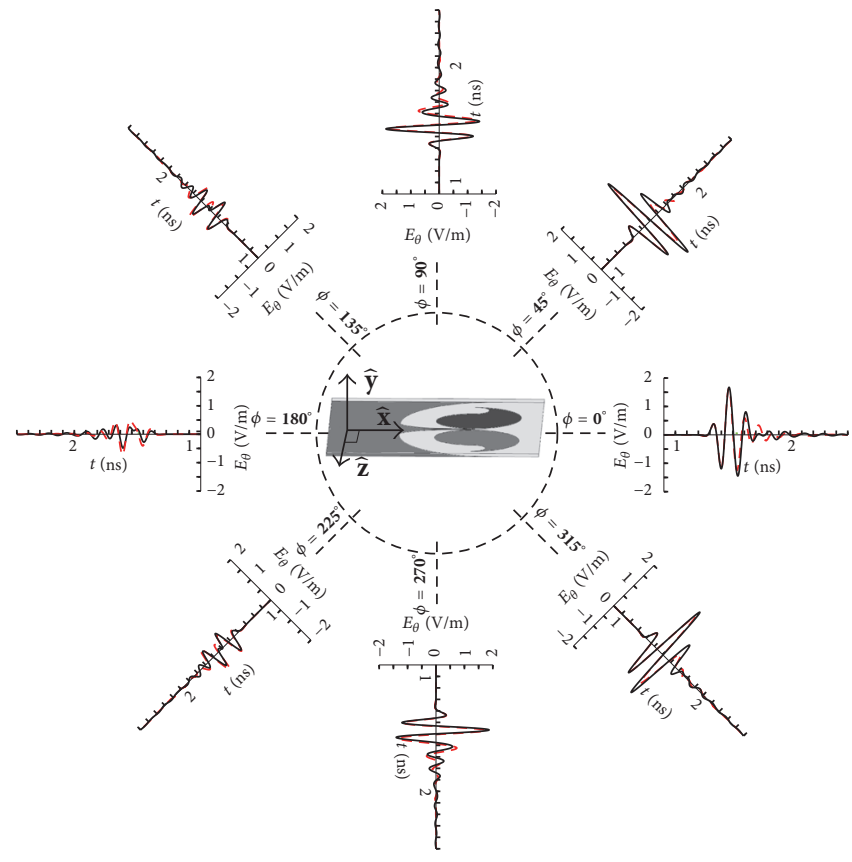

— Drop dip. with reflector

- - - Drop dip. without reflector

(b)

FIGURE 13: Time-domain behaviour of the electric field radiated by the antenna at a distance of $30 \mathrm{~cm}$ from the centre of the dipole arms: (a) in the $x z$-plane and (b) in the $x y$-plane. Characteristics of the excitation signal: $\sigma=51 \mathrm{ps.} \mathrm{The} \mathrm{effect} \mathrm{of} \mathrm{the} \mathrm{reflector} \mathrm{is} \mathrm{clearly} \mathrm{evident} \mathrm{in} \mathrm{the}$ figure.

and $R_{z_{q}}$ are the complex pole and the residues related to the $q$ th resonant process taking place in the radiating structure. The corresponding space-time domain expressions are found by means of the inverse Laplace transform which leads to the following result:

$$
\begin{aligned}
& e_{z}(x, t) \approx \frac{1}{x} \sum_{q=1}^{N_{\mathrm{pol}}} R_{z_{q}} e^{s_{q}(t-x / c)} u\left[t-\frac{x}{c}\right] * \frac{d}{d t} i_{0}(t), \\
& e_{y}(x, t) \approx 0
\end{aligned}
$$

where the symbol $*$ denotes the convolution product, while $u[\cdot]$ denotes the Heaviside unit-step function. Equations (7)(8) clearly show how the far-field waveforms are linked to the derivative of the current excitation signal $i_{0}(t)$. The poles $s_{q}$ and the residues $R_{z_{q}}$ in (7), evaluated along the boresight, by means of a modified pole/residue representation [32, 33], are reported in Figure 14. In particular, the number of poles, $N_{\text {pol }}$, is selected in such a way that the relative deviation, evaluated in $L^{2}$ norm, between the electric field radiated by the antenna, 


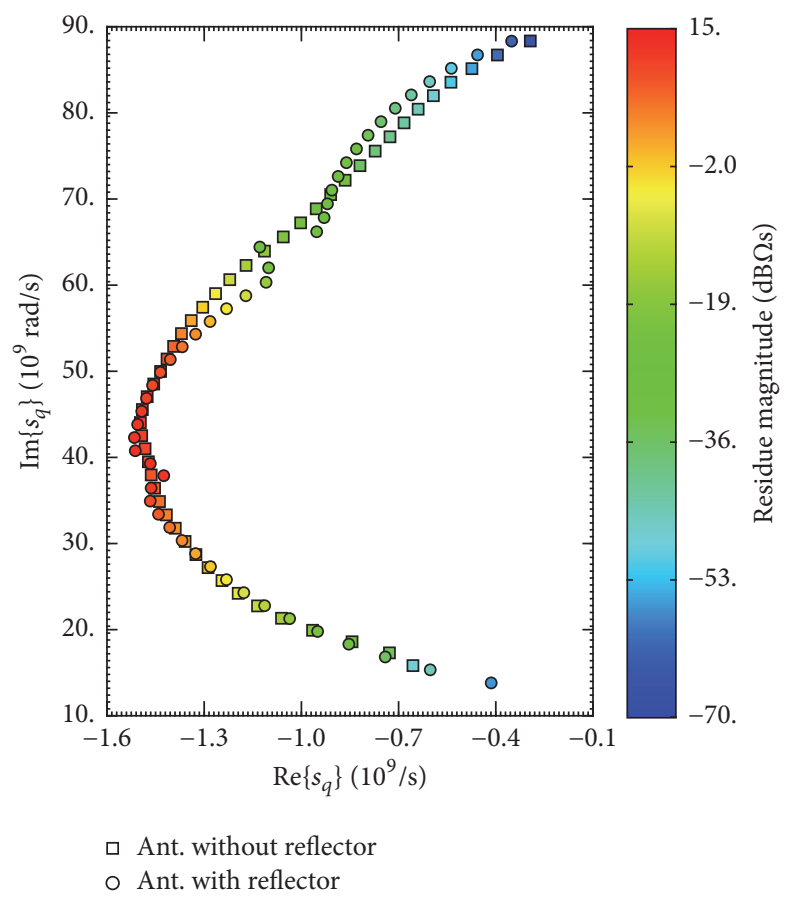

FIGURE 14: Location, in the complex $s$-plane, of the SEM-based dominant poles of the time-domain response of the drop-shaped antenna with and without reflector. The magnitude of the residues associated with each pole is marked with a specific colour. For the sake of clarity only the poles distributed in the second quadrant of the complex $s$-plane are reported in the figure.

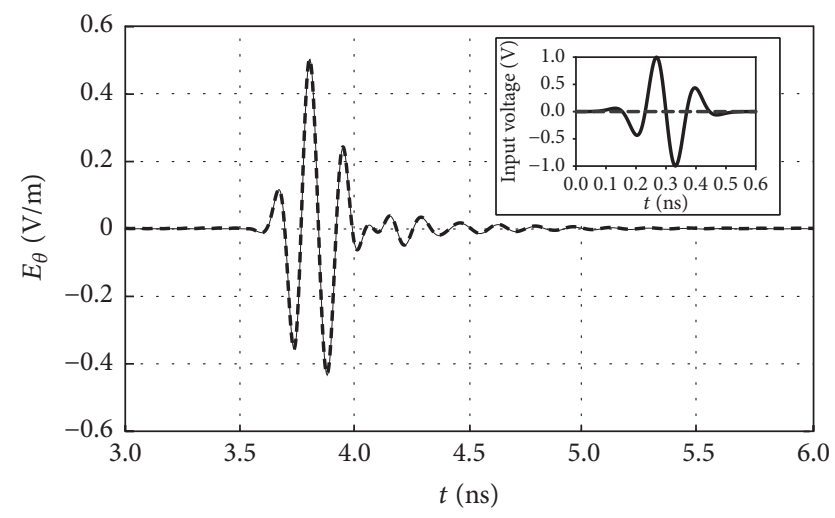

Ant. with reflector

$$
\text { —_ FDTD }
$$

(a)

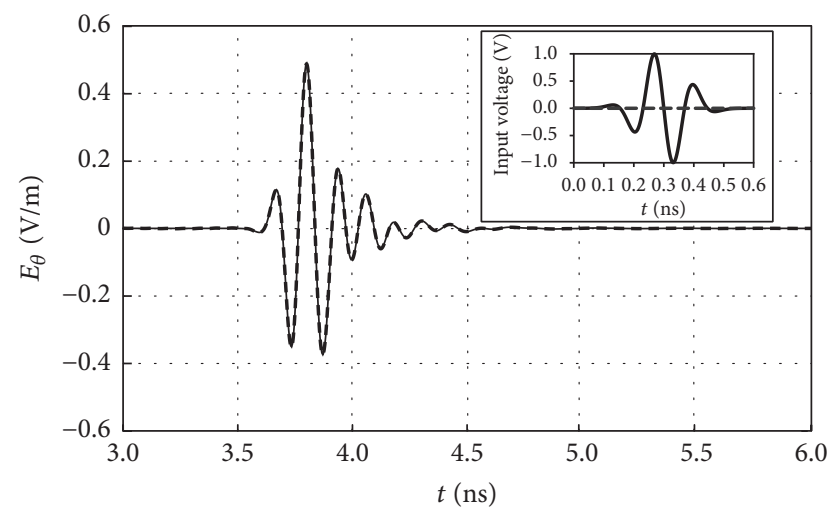

Ant. without reflector

- FDTD

--- SEM

FIGURE 15: Time-domain antenna response computed at $x=1 \mathrm{~m}$ along the boresight of the drop-shaped antenna (a) with reflector and (b) without reflector. The migration of some poles towards higher frequencies is responsible for a larger ripple level in the late-time response of the antenna equipped with the metal reflector.

$e_{z}(x, t)$, and the relevant residue/pole expansion, $e_{z}^{(\mathrm{SEM})}(x, t)$, is smaller than a given threshold $\delta$; namely,

$$
\frac{\left\|e_{z}(x, t)-e_{z}^{(\mathrm{SEM})}(x, t)\right\|_{2}}{\left\|e_{z}(x, t)\right\|_{2}}<\delta .
$$

In the proposed study, $\delta$ has been set equal to $1 \%$ in order to ensure an adequate accuracy of the representation.
By comparing the poles configurations in the complex $s$-plane (see Figure 14) for the two considered antennas, it appears that the reflector is responsible for a migration of some poles with respect to the antenna without reflector. These poles, linked with higher oscillation frequencies, result in a signal having slightly more pronounced undulations in the late-time response. This behaviour is confirmed by the antenna time-domain response reported in Figure 15. 


\section{Conclusions}

A low-profile printed drop-shaped dipole antenna integrated with a planar metal reflector has been presented. Parameterized equations describing the reflector and the feeding line profiles have been introduced to optimize and make the antenna design easy. A suitable shaping of the reflector and of the feeding line, as well as the adoption of a thin substrate having a low dielectric permittivity, has been selected in order to achieve a bandwidth larger than $10 \mathrm{GHz}$ and meet, in this way, the demanding requirements of different communication standards, such as WLAN/WiMAX and UWB protocols. The analysis of the radiated flux power density, performed by means of a full-wave locally conformal FDTD numerical technique, has shown that the energy emission substantially takes place along the edges of the reflector, as well as along the dipole radiating arms. In particular, it has been observed that the quasi-traveling wave behaviour of the radiated field induced by the special shape of the radiating arms is enhanced by the presence of the metal reflector already at the lowest working frequency of the antenna. Furthermore, an increment of the antenna gain and of the front-to-back ratio, in the frequency range where the main wireless communication systems operate, often overlooked in antenna design, has been achieved. This important feature can be exploited to reduce parasitic coupling with radio frequency circuitry sharing the same board in wireless communication systems and radio base stations. Finally, the small variation of the relative delay spread caused by the reflector does not excessively affect the time-domain response of the antenna making the antenna suitable also for UWB applications. This characteristic is confirmed by the SEM analysis which shows a weak migration of some poles of the time-domain response of the antenna caused by the presence of the reflector. In conclusion, the low profile, the reduced dimensions, the wide-band behaviour, and the limited back radiation make the proposed antenna suitable to be easily integrated in mobile devices and radio base stations.

\section{Conflicts of Interest}

The authors declare that there are no conflicts of interest regarding the publication of this paper.

\section{References}

[1] J. Martínez-Fernández, J. M. Gil, and W. Wiesbeck, “Twin Orthogonally Polarized UWB Aperture Antenna Elements With Optimized Profile Feed for Optimal Adaptation," IEEE Antennas and Wireless Propagation Letters, vol. 8, pp. 517-521, 2009.

[2] Y. Ranga, K. P. Esselle, A. R. Weily, and A. K. Verma, "An ultrawideband printed monopole antenna with the gain enhanced using a surface-mounted horn," in Proceedings of the 4th European Conference on Antennas and Propagation (EuCAP'10), pp. 1-4, Barcelona, Spain, April 2010.

[3] G. Cappelletti, D. Caratelli, and R. Cicchetti, "A locally conformal FDTD analysis of a thin printed antenna for wideband wireless applications," International Journal of Numerical Modelling:
Electronic Networks, Devices and Fields, vol. 24, no. 3, pp. 257270, 2011.

[4] G. Cappelletti, D. Caratelli, R. Cicchetti, and M. Simeoni, "A low-profile printed drop-shaped dipole antenna for wideband wireless applications," IEEE Transactions on Antennas and Propagation, vol. 59, no. 10, pp. 3526-3535, 2011.

[5] Q. Wu, S. Wang, and X. Sun, "Nonplanar dipole antennas for low-profile ultrawideband applications: design, modeling, and implementation," IEEE Antennas and Wireless Propagation Letters, vol. 11, pp. 897-900, 2012.

[6] F. Gao, F. Zhang, L. Lu, T. Ni, and Y. Jiao, "Low-profile dipole antenna with enhanced impedance and gain performance for wideband wireless applications," IEEE Antennas and Wireless Propagation Letters, vol. 12, pp. 372-375, 2013.

[7] K. Agarwal, Nasimuddin, and A. Alphones, "Unidirectional wideband circularly polarised aperture antennas backed with artificial magnetic conductor reflectors," IET Journal Microwave, Antennas \& Propagation, vol. 7, no. 5, pp. 338-346, 2013.

[8] M. Li and K.-M. Luk, "A low-profile wideband planar antenna," IEEE Transactions on Antennas and Propagation, vol. 61, no. 9, pp. 4411-4418, 2013.

[9] Y.-P. Zhang and C.-M. Li, "Design of small dual band-notched UWB slot antenna," Electronics Letters, vol. 51, no. 22, pp. 17271728, 2015.

[10] R. Cicchetti, A. Faraone, D. Caratelli, and M. Simeoni, "Wideband, multiband, tunable, and smart antenna systems for mobile and UWB wireless applications 2014," International Journal of Antennas and Propagation, vol. 2015, Article ID 536031, 3 pages, 2015.

[11] S. Verma and P. Kumar, "Printed Newton's egg curved monopole antenna for ultrawideband applications," IET Microwaves, Antennas and Propagation, vol. 8, no. 4, pp. 278-286, 2014.

[12] A. T. Mobashsher and A. Abbosh, "Utilizing symmetry of planar ultra-wideband antennas for size reduction and enhanced performance," IEEE Antennas and Propagation Magazine, vol. 57, no. 2, pp. 153-166, 2015.

[13] M. S. Ellis, Z. Zhao, J. Wu, Z. Nie, and Q. H. Liu, "Small planar monopole ultra-wideband antenna with reduced ground plane effect," IET Microwaves, Antennas \& Propagation, vol. 9, no. 10, pp. 1028-1034, 2015.

[14] R. Cicchetti, E. Miozzi, and O. Testa, "Wideband and UWB antennas for wireless applications: a comprehensive review," International Journal of Antennas and Propagation, vol. 2017, Article ID 2390808, 45 pages, 2017.

[15] K. Y. Yazdandoost, "UWB loop antenna for in-body wireless body area network," in Proceedings of the 7th European Conference on Antennas and Propagation (EuCAP '13), pp. 1138-1141, Gothenburg, Sweden, April 2013.

[16] B. S. Cook and A. Shamim, "Utilizing wideband AMC structures for high-gain inkjet-printed antennas on lossy paper substrate," IEEE Antennas and Wireless Propagation Letters, vol. 12, pp. 76-79, 2013.

[17] B. Liu, J. Han, S. Hu, and L. Zhang, "Novel multiband metalrimmed antenna for wearable applications," International Journal of Antennas and Propagation, vol. 2015, Article ID 319894, 7 pages, 2015.

[18] Z. H. Jiang and D. H. Werner, "A compact, wideband circularly polarized co-designed filtering antenna and its application for wearable devices with low SAR," IEEE Transactions on Antennas and Propagation, vol. 63, pp. 3808-3818, 2015. 
[19] P. Mousavi, "Multiband multipolarization integrated monopole slots antenna for vehicular telematics applications," IEEE Transactions on Antennas and Propagation, vol. 59, no. 8, pp. 31233127, 2011.

[20] T. Varum, J. N. Matos, P. Pinho, and A. Oliveira, "Printed antenna for DSRC systems with omnidirectional circular polarization," in Proceedings of the 15th International IEEE Conference on Intelligent Transportation Systems (ITSC '12), pp. 475-478, Anchorage, Alaska, USA, September 2012.

[21] D. V. Navarro-Méndez, L. F. Carrera-Suárez, E. AntoninoDaviu et al., "Compact wideband vivaldi monopole for LTE mobile communications," IEEE Antennas and Wireless Propagation Letters, vol. 14, pp. 1068-1071, 2015.

[22] X. Chen, J. Liang, S. Wang, Z. Wang, and C. Parini, "Small ultra wideband antennas for medical imaging," in Proceedings of the Loughborough Antennas \& Propagation Conference (LAPC '08), pp. 28-31, Loughborough, UK, March 2008.

[23] A. Sabban, "New wideband printed antennas for medical applications," IEEE Transactions on Antennas and Propagation, vol. 61, no. 1, pp. 84-91, 2013.

[24] P. Bernardi, R. Cicchetti, S. Pisa, E. Pittella, E. Piuzzi, and O. Testa, "Design, realization, and test of a UWB radar sensor for breath activity monitoring," IEEE Sensors Journal, vol. 14, no. 2, pp. 584-596, 2014.

[25] Y. Chen, W. T. Joines, Z. Xie, G. Shi, Q. H. Liu, and L. Carin, "Double-sided exponentially tapered GPR antenna and its transmission line feed structure," IEEE Transactions on Antennas and Propagation, vol. 54, no. 9, pp. 2615-2623, 2006.

[26] F. Zhang, G.-Y. Fang, Y.-C. Ji, H.-J. Ju, and J.-J. Shao, "A novel compact double exponentially tapered slot antenna (DETSA) for GPR applications," IEEE Antennas and Wireless Propagation Letters, vol. 10, pp. 195-198, 2011.

[27] A. F. Molisch, "Ultrawideband propagation channels-theory, measurement, and modeling," IEEE Transactions on Vehicular Technology, vol. 54, no. 5, pp. 1528-1545, 2005.

[28] L. B. Felsen and N. Marcuvitz, Radiation and Scattering of Waves, Prentice-Hall/IEEE Press, New York, NY, USA, 1994.

[29] D. Caratelli, R. Cicchetti, G. Bit-Babik, and A. Faraone, "Circuit model and near-field behavior of a novel patch antenna for WWLAN applications," Microwave and Optical Technology Letters, vol. 49, no. 1, pp. 97-100, 2007.

[30] K. Bahadori and Y. Rahmat-Samii, "A miniaturized elliptic-card UWB antenna with WLAN band rejection for wireless communications," IEEE Transactions on Antennas and Propagation, vol. 55, no. 11, pp. 3326-3332, 2007.

[31] T. K. Sarkar and O. Pereira, "Using the matrix pencil method to estimate the parameters of a sum of complex exponentials," IEEE Antennas and Propagation Magazine, vol. 37, no. 1, pp. 4855, 1995.

[32] D. Caratelli and A. Yarovoy, "Unified time- and frequencydomain approach for accurate modeling of electromagnetic radiation processes in ultrawideband antennas," IEEE Transactions on Antennas and Propagation, vol. 58, no. 10, pp. 32393255, 2010.

[33] R. Cicchetti, A. Faraone, E. Miozzi, R. Ravanelli, and O. Testa, "A high-gain mushroom-shaped dielectric resonator antenna for wideband wireless applications," IEEE Transactions on Antennas and Propagation, vol. 64, no. 7, pp. 2848-2861, 2016. 


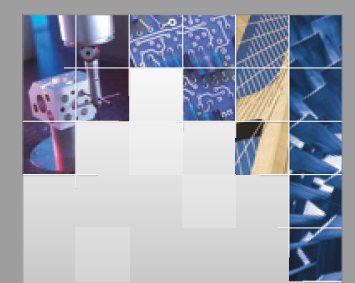

\section{Enfincering}
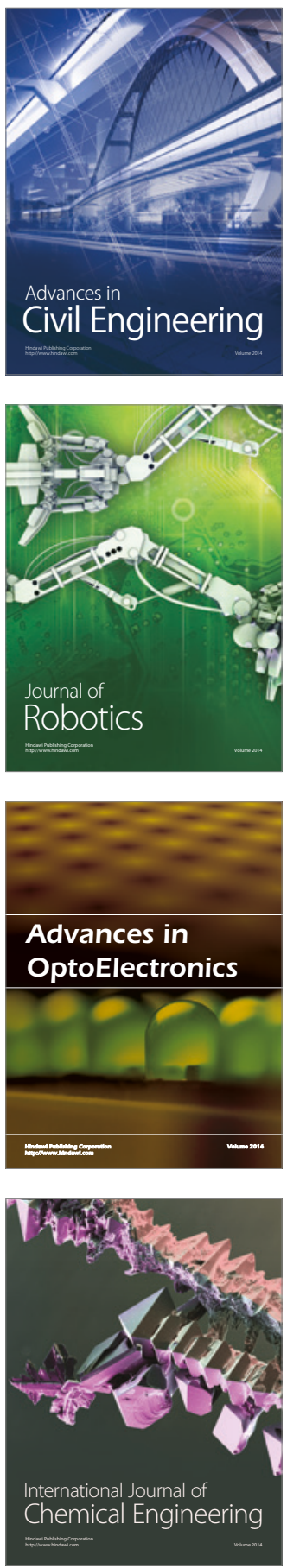

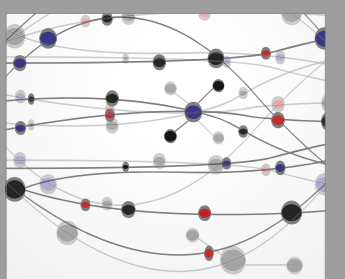

The Scientific World Journal

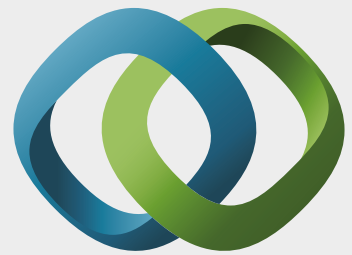

\section{Hindawi}

Submit your manuscripts at

https://www.hindawi.com
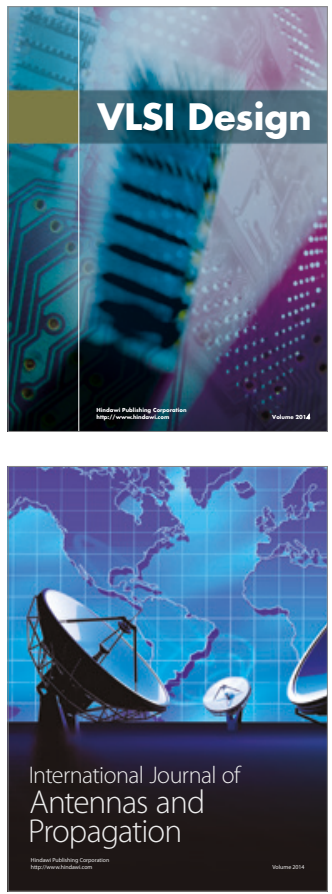

\section{Rotating}

Machinery
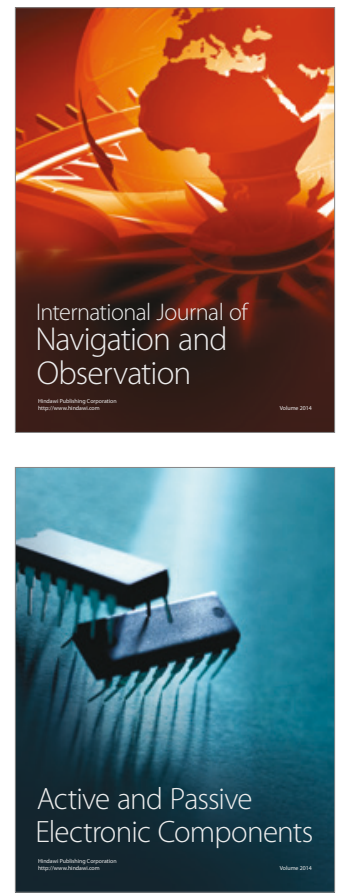
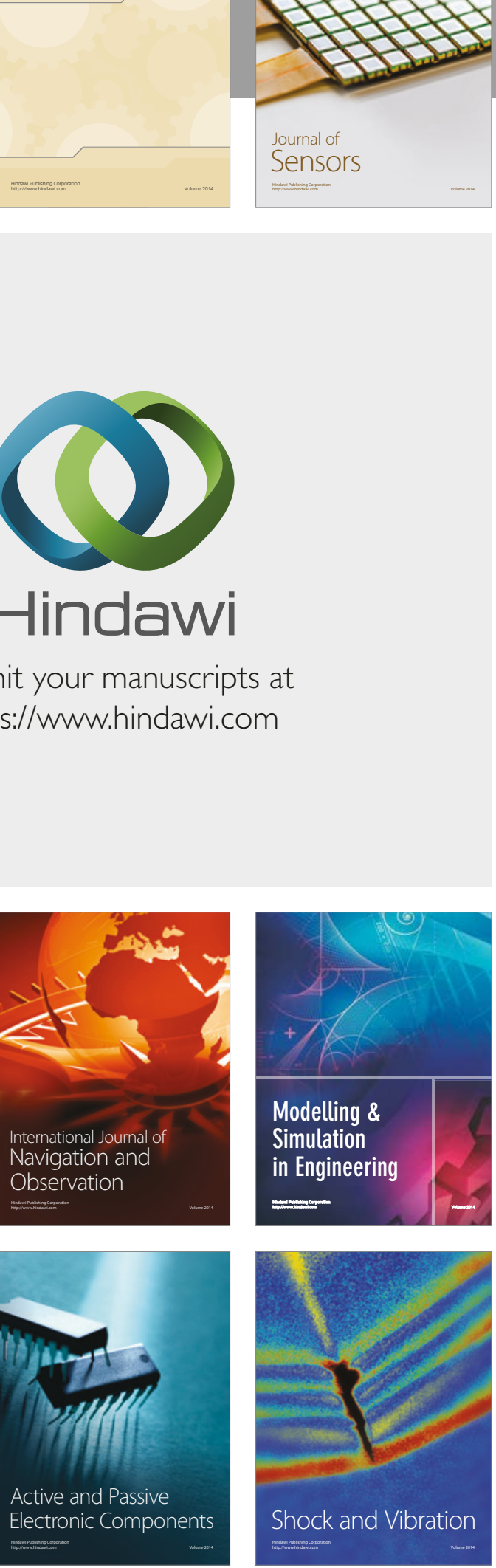
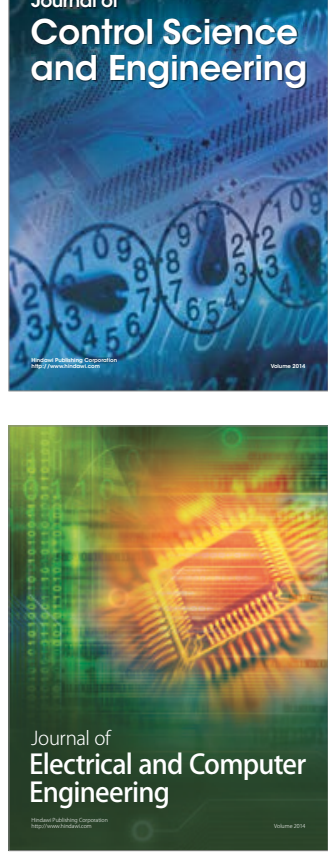

Distributed

Journal of

Control Science

and Engineering
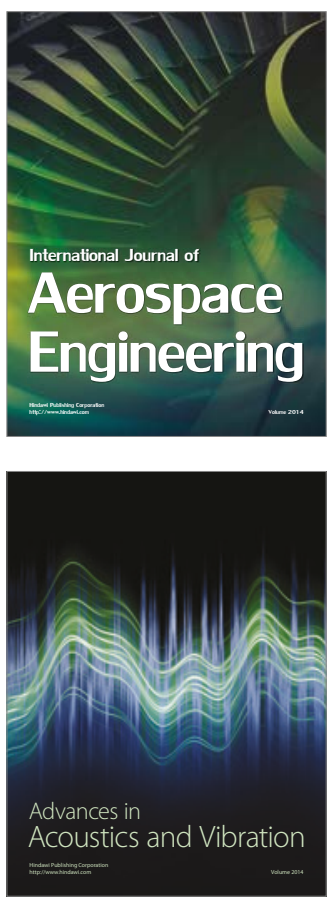

Sensor Networks 